\title{
DIREITO FUNDAMENTAL AO MEIO AMBIENTE E O PROCESSO ESTRUTURAL COMO MEIO ADEQUADO PARA SUA TUTELA
}

\author{
Tamara Brant Bambirra ${ }^{1}$ \\ Deilton Ribeiro Brasil ${ }^{2}$
}

\section{RESUMO}

O trabalho busca, através do método descritivo-analítico, trazer reflexões sobre a proteção aos direitos fundamentais, especialmente o direito ambiental e a necessidade de uma reestruturação e reorganização de políticas públicas. A justificativa reside no propósito de analisar se essa reestruturação pode se dar através de uma decisão estruturante capaz de efetivar a tutela do direito fundamental ao meio ambiente equilibrado, produzindo uma mudança estrutural relevante. A metodologia é baseada nas pesquisas documentais, doutrinárias e de revisões bibliográficas. Como resultados alcançados, constatou-se que o processo estrutural é meio adequado para a tutela de direitos fundamentais, sendo ele reparatório ou preventivo.

Palavras Chave: Meio ambiente; Decisões estruturais; Direitos fundamentais; Processo estrutural; Medidas estruturantes.

\section{FUNDAMENTAL RIGHT TO THE ENVIRONMENT AND THE STRUCTURAL PROCEDURE AS A SUITABLE WAY FOR ITS PROTECTION}

\begin{abstract}
This paper seeks, through the descriptive-analytical method, to bring reflections on the protection of fundamental rights, especially environmental law and the need for a restructuring and reorganization of public policies. The justification lies in the purpose of analyzing whether this restructuring can take place through a structuring decision capable of effecting the protection of the fundamental right to a balanced environment, producing a relevant structural change. The methodology is based on documentary, doctrinal and bibliographic reviews. As results achieved, it was found that the structural process is an adequate way for the protection of fundamental rights, be it reparative or preventive.
\end{abstract}

Keywords: Environment; Structural decisions; Fundamental rights; Structural procedure; Structuring measures.

\footnotetext{
${ }^{1}$ Mestranda do PPGD - Mestrado e Doutorado em Proteção dos Direitos Fundamentais da Universidade de Itaúna-MG. Pós-graduada em direito público e privado. Bacharel em Direito pela Faculdade Dom Hélder Câmara (ESDHC).

${ }^{2}$ Pós-Doutor em Direito pela UNIME, Itália. Doutor em Direito pela UGF/RJ. Professor da Graduação e do PPGD - Mestrado e Doutorado em Proteção dos Direitos Fundamentais da Universidade de Itaúna (UIT). Faculdades Santo Agostinho (FASASETE-AFYA) e Faculdade de Direito de Conselheiro Lafaiete (FDCL). Professor visitante do PPGD da Universidade de Caxias do Sul (UCS).
} 


\section{INTRODUÇÃO}

O processo estrutural surgiu nos Estados Unidos, entre 1950 e 1970, quando juízes federais procuraram implementar uma decisão da Suprema Corte, a partir de um ativismo judicial, que instituiu uma nova forma de atuação do poder Judiciário norte-americano.

O caso Brown v. Board of Education deixa clara uma das principais características das decisões estruturais, que é a sua função performativa e qualitativa, que se dá através da expansão das demandas judicializadas, alcançando resultados que estariam fora do que previamente se entendia possível de consubstanciar através de um debate judicial.

É notório que o Poder Judiciário muitas vezes não consegue respaldar violação de direitos fundamentais de um grupo ou de um grande número de pessoas de uma só vez. Sendo assim as decisões estruturais se apresentam como uma forma de solucionar essas demandas que envolvem um grupo de pessoas, cujo direito foi violado. Uma vez que se busca através da decisão estrutural implementar a reestruturação de uma organização, que se encontra em um estado de desequilíbrio estrutural, podendo ser uma situação de ilicitude ou uma situação que não condiz ao estado considerado como ideal, necessitando assim de uma reorganização, uma reestruturação.

O direito a um meio ambiente equilibrado, amparado pela Constituição Federal de 1988, muitas vezes é negligenciado. O Estado deveria assegurar meios preventivos para a preservação do meio ambiente, uma vez que normalmente a reparação do dano ecológico é incerto, através de medidas efetivas e de políticas de defesa ao meio ambiente, prezando por um ambiente saudável.

A primeira parte do artigo apresenta breves considerações acerca do processo estrutural. A segunda parte do trabalho discorre sobre o processo estrutural como instrumento adequado para a garantia dos direitos fundamentais. A terceira parte do artigo, por sua vez, tratará propriamente do processo estrutural como instrumento de tutela do direito fundamental ao meio ambiente equilibrado.

A justificativa do trabalho dá-se no propósito de analisar se o processo estrutural é instrumento jurisdicional adequado e eficaz para assegurar a tutela a um meio ambiente equilibrado. O objetivo do trabalho é demonstrar a necessidade de uma reestruturação e readequação das políticas públicas voltadas à proteção ao meio ambiente através de uma 
decisão estruturante capaz de efetivar a tutela do direito fundamental ao meio ambiente, produzindo uma mudança estrutural relevante.

O presente estudo utiliza-se da pesquisa bibliográfica. Valeu-se do método descritivoanalítico. Foi realizado a partir do estudo de dispositivos legais, artigos e doutrinas para apresentar melhor reflexão sobre o tema central da presente pesquisa. A metodologia da pesquisa é feita em três vertentes, que são elas a: documental, doutrinária e revisão bibliográfica.

\section{ALGUMAS CONSIDERAÇÕES SOBRE O PROCESSO ESTRUTURAL}

Um procedimento que se destine a discutir tutela dos direitos fundamentais em uma situação de desconformidade estruturada, exige uma amplitude muito maior do que a lógica bipolar dos processos comumente utilizados pelo ordenamento jurídico brasileiro. Exige uma maior participação das partes e até mesmo caso seja necessário a possibilidade de participação da sociedade, bem como uma ampliação da cognição do judiciário, de modo a permitir que o judiciário tenha contato com todo o problema, sob suas várias perspectivas. Os processos estruturais apresentam uma perspectiva de ruptura com a concepção tradicional da lide.

A noção de processo estrutural surgiu nos Estados Unidos, a partir do ativismo judicial que marcou a atuação do poder judiciário norte-americano entre 1950 e 1970 (JOBIM, 2013, p. 93). Tudo começou com o caso Brown v. Board of Education, no qual a Suprema Corte norte-americana entendeu que era inconstitucional a admissão de estudantes em escolas públicas americanas com base num sistema de segregação racial. Ao determinar a aceitação da matricula de estudantes negros numa escola pública até então dedicada a educação de pessoas brancas, a Suprema Corte deu início a um processo amplo de mudança do sistema público de educação naquele país, fazendo surgir o que se chamou de structural reform (FISS, 2008, p.761).

O processo coletivo estrutural nasceu de uma necessidade eminentemente prática em Brown v. Board of Education. O Chief Justice Warren, responsável pela decisão, adotou a posição de que ela deveria expressar um consenso da Corte, pois a mudança de entendimento que se pretendia realizar seria enfraquecida pela existência de votos vencidos (VITORELLI, 2021, p.335). 
É usual considerar o caso Brown v. Board of Education o caso mais emblemático da reforma estrutural. Neste famoso precedente a Suprema Corte norte-americana considerou inconstitucional a doutrina do separate but equal nas escolas. Mas não se limitou à declaração de inconstitucionalidade. Determinou ainda a adoção de medidas concretas e diferenciadas no tempo para erradicar o sistema escolar dual baseado na cor da pele. A politica de segregação racial foi superada, mas não sem fortes resistências fáticas e sérias impugnações jurídicas. (VIOLIN, 2021, p.638).

É importante mencionar o contexto histórico, uma vez que havia um racismo institucionalizado e uma segregação racial acentuada, inclusive endossado pela Suprema Corte no caso Plessy v. Ferguson, 1896, que até então era a base juridica para legitimar a segregação racial nos Estados Unidos, em locais como escolas, praças, hospitais, ônibus e trem.

Nos Estados Unidos o esforço para se impor judicialmente a realização de valores públicos, talvez o mais ambicioso exercício do poder jurisdicional, ficou conhecido como public law litigation, ou ações de interesse público. Esse movimento que surgiu em meados da década de 1950, com os esforços para o combate à segregação escolar, foi rapidamente expandido para o racismo e a discriminação em outros setores, a reforma de prisões, hospitais, combate a comportamentos ambientais lesivos, dentre outras formas de realização de direitos fundamentais (VITORELLI, 2021, p.331).

O caso Brown $x$ Board of Education foi um caso complicado que resultou em dois fenômenos correlacionados, a impossibilidade de compreensão e resolução integral do tema e a consequente necessidade de se deslocar parte do processo decisório para etapas posteriores, é o que Sérgio Arenhart (2013, p.400) denomina de decisões em cascata.

Brown insere-se no contexto social do movimento pelos direitos civis que tomou corpo nos Estados Unidos entre 1954 e 1968. Esse período foi marcado por conflitos raciais e por grandes manifestações em favor da igualdade, bem como por violentas reações contrárias. O civil rights movement irradiou efeitos no âmbito jurídico, que recepcionou os anseios por mudança. O direito processual traduziu a pretensão de reconstrução das relações sociais, especialmente aquelas baseadas em critérios raciais, como uma forma especial de processo, chamada de reforma estrutural (VIOLIN, 2021, p.638).

Se as decisões judiciais se mostraram insuficientes para erradicar o racismo endêmico, não apenas naquela comunidade, em contrapartida, contribuíram para reduzir as 
desigualdades e para enfraquecer gradativamente o modelo separate but equal (SILVA NETO, 2021, p. 409).

Outro bom exemplo são os casos Holt v. Sarver, por meio dos quais o sistema prisional do estado do Arkansas, nos Estados Unidos, foi judicialmente impugnado, em demandas que visavam a reforma completa do sistema penitenciário e que serviram de base para outras demandas similares, deflagradas posteriormente, em 1993, contra quarenta outros estados norte-americanos (VIOLIN, 2019, p.505).

Num dos casos mais interessantes da era Warren, Holt v. Sarver, pôs-se em xeque a constitucionalidade do sistema prisional do Estado do Arkansas em sua integralidade. Ao contrário do que pode parecer, Holt v. Sarver não é um litígio, mas um conjunto formado por pelo menos seis causas entre ações e recursos que tramitaram entre 1969 e 1982. (VIOLIN, 2021, p.639).

Neste referido caso, os detentos alegaram uma política cruel e irrazoável de confinamento, falta de assistência médica e odontológica e até mesmo incapacidade do Estado em proteger os apenados de ataques de outros internos. A Suprema Corte então entendeu que as condições de detenção no Estado de Arkansas eram inconstitucionais, mas não impôs as medidas que deveriam ser tomadas, estabeleceu diretrizes para humanizar as prisões e ofereceu à administração prisional a oportunidade de estabelecer um plano para sanar as violações constatadas, que ficaria sob a supervisão da Corte.

É de grande importância a força simbólica dos dois casos supra, Brown x Board of Education e Holt v. Sarver, sendo tão significativos que as suas características foram utilizadas para descrever um modelo de processo novo, os processos estruturais. Em ambos os casos os juízes decidiram que as mudanças e adequações deveriam ser feitas de forma gradual, com medidas que permitissem o feito, mas com toda velocidade diante das possibilidades.

Desde o início, esses movimentos foram confrontados com o fato de que, para realizar o intento buscado no processo, havia necessidade de se romper com a estrutura tradicional de direito, obrigação, violação e reparação. Indenizar aqueles que sofreram com o ilícito é ineficaz para se atingir o objetivo de realizar o interesse público, porque não se impede que as violações continuem ocorrendo. É preciso tomar a violação como ponto de partida para encontrar formas de cessar o comportamento que origina ou o contexto estrutural que a favorece (VITORELLI, 2021, p.331). 
A complexidade do litígio estrutural consiste na impossibilidade de compreendê-lo holisticamente, sobretudo na fase de conhecimento, o que gera a impossibilidade de se preverem, de logo, todos os comportamentos humanos necessários à resolução do problema. Diante disso, convém que a sentença assuma também uma menor carga de densidade, consignando o estado de coisas almejadas e as diretrizes adotadas para o seu processo de implementação (SILVA NETO, 2021, p. 413-416).

A caracterização de um litígio estrutural envolve a superposição de algumas características. Primeiro trata-se de um conflito de elevada complexidade que envolve múltiplos pólos de interesse, os quais se apresentam em oposições e alianças parciais. Segundo o litígio estrutural implica a implementação, pela via jurisdicional, de valores públicos reputados juridicamente relevantes, mas que não foram bem-sucedidos espontaneamente na sociedade. Em terceiro lugar, o litígio estrutural se diferencia pela necessidade de reforma de uma instituição pública ou privada, para permitir a promoção do valor público visado, essa instituição pode ser a protagonista da violação do direito material ou pode obstaculizar a sua promoção. De todo modo, no contexto de um litígio estrutural, a tutela jurisdicional efetiva e duradoura é condicionada à alteração do comportamento institucional. A reestruturação da instituição é que permite a autossustentabilidade do valor promovida pela demanda. (VITORELLI, 2021, p.331-332)

Ao se referir a essa forma de atuação do poder judiciário, a doutrina enfatiza, a forte incidência de princípios constitucionais, a necessidade de se reestruturar uma instituição ou políticas públicas, a existência de vários ciclos de decisões e uma maior carga de ativismo judicial. Sob essa ótica, a categoria dos processos estruturais não se esgota, obviamente, no campo das técnicas e dos institutos processuais. (SILVA NETO, 2021, p. 410)

$\mathrm{O}$ conceito de processo estrutural pressupõe o de problema estrutural. O problema estrutural se define pela existência de um estado de desconformidade estruturada, uma situação de ilicitude contínua e permanente ou uma situação de desconformidade, ainda que não propriamente ilícita, no sentido de ser uma situação que não corresponde ao estado de coisas considerado ideal. Como quer que seja, o problema estrutural se configura a partir de um estado de coisa que necessita uma reorganização ou de reestruturação (DIDIER; ZANETI; OLIVEIRA, 2021, p.427).

Estado de desconformidade é a situação de desorganização estrutural, de rompimento com a normalidade ou com o estado ideal de coisas, que exige uma intervenção reestruturante. 
Essa desorganização pode ou não ser consequência de um conjunto de atos ou condutas ilícitas. O que queremos frisar é que o problema estrutural não necessariamente se assenta na noção de ilicitude e, quando eventualmente nela se assenta, não se confunde, ele mesmo com as situações ilícitas que dela advêm. O seu tratamento não é a partir da noção de ilicitude, muito embora ela possa ocorrer e quase sempre ocorra (DIDIER; ZANETI; OLIVEIRA, 2021, p.427).

O importante é notar que existindo esse estado de desconformidade, a solução do problema não pode dar-se com apenas um único ato, como uma decisão que certifique um direito e imponha uma obrigação. Há necessidade de intervenção para promover a reorganização ou reestruturação da situação. Essa intervenção normalmente é duradoura e exige um acompanhamento contínuo (GALDINO, 2019, p.705).

O objetivo imediato do processo estrutural é alcançar o estado ideal de coisas, um sistema educacional livre de segregação, um sistema prisional em que seja asseguradas a dignidade do preso e a possibilidade de ressocialização, um sistema de saúde universal e isonômico, e também, por exemplo, a preservação da empresa recuperanda. Busca-se remover o estado de desconformidade, promovendo uma transição para o estado de conformidade (DIDIER; ZANETI; OLIVEIRA, 2021, p.431).

Com efeito, variando o objeto da ação, variam também as adaptações procedimentais necessárias à proteção do bem da vida. A tutela do direito à saúde, à habitação ou à erradicação do trabalho infantil, por exemplo, exigirá medidas diversas daquelas adotadas para a dessegregação das escolas. Daí a importância de se estudarem casos que envolvam outras pretensões além da igualdade racial no sistema educacional. A discriminação da mulher no mercado de trabalho, as condições dos presídios, o tratamento nas instituições psiquiátricas e a prevenção de danos ambientais, são alguns temas que podem dar origem a pretensões estruturais (VIOLIN, 2021, p.639).

A decisão estrutural é aquela que partindo da constatação de um estado de desconformidade, estabelece o estado ideal de coisas que se pretende implantar, fim, e o modo pelo qual esse resultado deve ser alcançado, meios. Em essência a decisão estrutural não estrutura, mas sim reestrutura o que estava desorganizado (DIDIER; ZANETI; OLIVEIRA, 2021, p.431-432).

Sendo assim, o objetivo do processo estrutural, visando a concretização do que foi decidido, é atingir o estado ideal, buscando tutelar direitos fundamentais através de uma 
reestruturação, uma reorganização de instituições que violam os direitos dos indivíduos devido a uma má performance no exercício de suas atribuições, em virtude de uma falha estrutural.

\section{PROCESSO ESTRUTURAL COMO MECANISMO PARA A EFETIVIDADE DOS DIREITOS FUNDAMENTAIS}

A Constituição Federal de 1988 instaurou uma nova ordem jurídica, proclamando o Brasil como um Estado democrático. Configurando assim que devido ao seu sistema institucional, no Brasil cada um deve ter os seus direitos respeitados, direitos estes que estão presentes em regras previamente estabelecidas, como os direitos fundamentais e direitos humanos assegurados pela Constituição e Tratados Internacionais nos quais o Brasil é signatário.

Sendo assim, com a adoção de um Estado democrático, houve também a expansão do rol de direitos fundamentais na Constituição, sendo que também foi limitado o poder Estatal e concedido maior valor à soberania popular.

O direito a um mínimo existencial para uma vida digna tem sido presença constante no debate acadêmico e jurisdicional brasileiro, especialmente na sua articulação com os direitos fundamentais sociais. Todavia, é precisamente na esfera dos direitos fundamentais sociais que se percebe, à vista dos desenvolvimentos na esfera doutrinária e jurisprudencial, o quanto o recurso à noção de um mínimo existencial, designadamente de um direito fundamental à sua proteção e promoção, tem sido realmente produtiva, mas também apresenta aspectos dignos de maior reflexão quanto à sua correta compreensão e manejo (SARLET, 2021, p. 605)

É importante reconhecer que a promulgação da Constituição Federal de 1988, não apenas estabeleceu um regime democrático, como também propiciou um grande avanço no que tange os direitos e garantias fundamentais. A Carta Magna faz menção expressa à proteção dos direitos humanos, bem como emprega como fundamentos da República Federativa a cidadania e a dignidade da pessoa humana.

Dignidade da pessoa humana é uma qualidade intrínseca e distintiva de cada ser humano que o faz merecedor do mesmo respeito e consideração por parte do Estado e da comunidade, implicando, neste sentido, um complexo de direitos e deveres fundamentais que assegurem a pessoa tanto contra todo e qualquer ato de cunho degradante e desumano, como 
venham a lhe garantir as condições existenciais mínimas para uma vida saudável, além de propiciar e promover sua participação ativa e corresponsável nos destinos da própria existência e da vida em comunhão com os demais seres humanos (SARLET, 2012, p.62).

Entretanto, mesmo reconhecendo a sua existência, conceituar dignidade da pessoa humana continua a ser um enorme desafio. Isto porque tal conceito encontra-se no rol daqueles considerados vagos e imprecisos. É um conceito, na verdade, que, desde a sua origem, encontra-se em um processo contínuo de construção. Não podemos, de modo algum, construirmos contornos precisos a ele, justamente por ser um conceito aberto. Percebe-se, entretanto, a preocupação do legislador constituinte em conceder um status normativo ao princípio da dignidade da pessoa humana, entendendo-o como um dos fundamentos do Estado Democrático de Direito (GRECO, 2011, p. 57-71).

Convém destacar ainda que a dignidade implica uma dimensão sociocultural e que é igualmente considerada como carente de respeito e promoção pelos órgãos estatais, razão pela qual, prestações básicas em matéria de direitos e deveres culturais, notadamente no caso da educação fundamental e destinada a assegurar uma efetiva possibilidade de integração social, econômica, cultural e política ao indivíduo, mas também o acesso a alguma forma de lazer, estariam sempre incluídas no mínimo existencial, o que também corresponde, em termos gerais, ao entendimento consolidado na esfera da doutrina brasileira sobre o tema (SARLET, 2021, p. 617).

O reconhecimento dos direitos fundamentais do homem, no ordenamento jurídico, em enunciados explícitos nas declarações de direitos, é coisa recente, e está longe de se esgotarem suas possibilidades, já que a cada passo na etapa da evolução da Humanidade importa na conquista de novos direitos. Mais que conquista, o reconhecimento desses direitos caracteriza-se como reconquista de algo que, em termos primitivos, se perdeu (SILVA, 2007, p.153)

A atual noção de um direito fundamental ao mínimo existencial, ou seja, de um direito a um conjunto de prestações estatais que assegure a cada um uma vida condigna, arranca da ideia de que qualquer pessoa necessita que não tenha condições de, por si só ou com o auxílio de sua família prover o seu sustento, tem direito ao auxílio por parte do Estado e da sociedade, de modo que o mínimo existencial, nessa perspectiva, guarda alguma relação com a noção de caridade e com o combate à pobreza (SARLET, 2021, p. 607). 
Isso assume particular relevância quando se cuida de invocar o mínimo existencial como critério para balizar uma ponderação no contexto das decisões que envolvem o reconhecimento, ou não, de um direito subjetivo a prestações sociais, dadas as colisões e tensões com outros direitos fundamentais ou outros princípios e regras de matriz constitucional e legal, mas também, em especial, em face dos limites fáticos postos pelo problema de escassez de recursos (SARLET, 2021, p. 606).

As omissões do Estado resultam em uma grande violação de direitos fundamentais que decorrem de falhas estruturais, que devem ser reconhecidas por não tornar realidade o que está disposto no texto constitucional. Sendo a judicialização uma consequência do modelo institucional vigente.

Em razão da peculiaridade destes direitos, que clamam por uma efetiva gestão, não basta a previsão legal destes, bem como do procedimento a ser adotado para a respectiva tutela. Faz-se necessário transformar os institutos jurídicos apresentados em instrumentos adequados na solução do litígio apresentado à autoridade competente, a começar pela sentença, onde se é exteriorizada a decisão motivada tendente a solucionar o conflito e, por conseguinte, efetivar tais direitos e alcançar o pleno acesso à justiça (ARAÚJO, 2021, p. 1136).

Tudo isso somado, já nos aproxima do tema das assim chamadas decisões ou medidas de caráter estruturante, na esfera das quais os Tribunais, em se tratando de direitos sociais a prestações, geralmente não deferem pedidos na condição de direitos subjetivos individuais ou mesmo coletivamente, de modo direto, mas de modo mais ou menos enfático e detalhado apontam determinados caminhos e medidas que devem ser levadas a efeito. Decisões estruturantes servem para assegurar uma solução unitária e mais sistemática, mas precisamente em virtude da resistência em relação ao seu cumprimento espontâneo não podem afastar demandas pontuais para correção dos problemas mais emergenciais existentes (SARLET, 2021, p. 627-629).

Sendo assim, o processo estrutural pode ser visto como uma medida que busca a efetivação de direitos fundamentais tutelados pela Constituição Federal, existindo a necessidade de um debate aberto para se chegar a melhor interpretação e adequação do caso.

Quando se trata de direitos fundamentais ou até mesmo quando se discute políticas públicas em via judicial, é necessário a participação dos destinatários daquela decisão, para se produzir uma interpretação mais próxima possível da realidade. Visto que, no processo de 
interpretação constitucional estão potencialmente vinculados todos os órgãos estatais, todas as potências públicas, todos os cidadãos e grupos, não sendo possível estabelecer-se um elenco cerrado ou fixado com numerus clausus de intérpretes da Constituição (COELHO, 1998, p. 157-158)

Posto isso, é inegável que a legitimidade das soluções consensuais sobre políticas públicas e também sobre direitos fundamentais violados, dependem, indubitavelmente, da permeabilidade das negociações à participação dos grupos que podem ser atingidos e de especialistas no tema (ARENHARDT, 2015, p. 16).

O sistema de reforma estrutural não tem cunho individualista, tampouco é caracterizado pela não participação do poder judiciário, ao contrário, o Estado juiz dirige e rege a reconstrução das instituições a fim de efetivar valores públicos. (ARAÚJO, 2021, p. 1137).

Inquestionavelmente, tem-se, neste cenário, o sistema judiciário adentrando e moldando o sistema político com vistas a garantir os valores constitucionais. Por esta razão, a atuação dos agentes do sistema judiciário em pleno Estado de Direito revela-se necessária e legítima diante dos litígios complexos que lhe são apresentados (ARAÚJO, 2021, p. 1139 1140).

Pela via democrática direta e com ampla participação da sociedade, que se busca suprir a baixa resolutividade das figuras tradicionais do Poder Judiciário, por meio do processo estrutural que deve se assemelhar a uma ampla arena de debate, em que as várias posições e os vários interesses possam fazer-se ouvir e possam interferir na formação da solução jurisdicional (JOBIM, 2021, p. 448)

Além disso, o manejo adequado das decisões judiciais do tipo estruturante poderá então colaborar efetivamente para inibir uma litigância errática e individualizada, além de contribuir para uma cultura de diálogo, e o que segue sendo uma das principais carências, de respeito institucional, e ainda visa produzir efeitos de racionalização, organização do processo e da sua efetividade (SARLET, 2021, p. 635).

Deste modo, condutas baseadas em diálogos tendem alcançar uma maior legitimidade e aplicabilidade, sendo que a interação entre o poder judiciário, instituições públicas ou privadas e sociedade pode alcançar melhores resultados práticos. Será alcançada melhores decisões através do diálogo, uma vez que assim poderá se perceber os limites da capacidade e legitimidade para cumprimento daquela decisão, buscando uma maior contribuição para a 
concretização do valor público, por parte das instituições, dos indivíduos e dos grupos que tiveram seus interesses afetados.

\section{PROCESSO ESTRUTURAL COMO MEIO EFICAZ DE TUTELA DO MEIO AMBIENTE COMO DIREITO FUNDAMENTAL}

A Segunda Guerra Mundial proporcionou diversas alterações na comunidade internacional, houve um significativo desenvolvimento tecnológico e científico, e a sociedade em geral passou a reivindicar por direitos que transcendem o individual e o social.

Depois de preocupações em torno da liberdade e das necessidades humanas, surge uma nova convergência de direitos, volvida à essência do ser humano, sua razão de existir, ao destino da humanidade, pensando o ser humano enquanto gênero e não adstrito ao indivíduo ou mesmo a uma coletividade determinada (ARAÚJO, 1999, p.78).

Em 1972, com a Declaração de Estocolmo, houve o reconhecimento do direito ao meio ambiente como um direito fundamental, ou seja, o direito a um ambiente equilibrado que proporciona uma vida saudável, o direito a uma vida digna em um ambiente de qualidade. A Declaração de Estocolmo determinou uma obrigação de melhor proteção ao meio ambiente, para as gerações presentes e futuras, estabelecendo um dever de cuidado com o ambiente uma vez que a saúde da população depende diretamente do equilíbrio ambiental (TOSTES, 1994, p. 119).

O direito ao meio ambiente, com a Conferência de Estocolmo, passou a ser identificado como direito fundamental de terceira dimensão, devido ao seu caráter transindividual. Ou seja, com a chegada de um sistema especial de proteção internacional aos direitos fundamentais, aparece também uma nova dimensão desses direitos, os direitos da humanidade. Estes têm por objeto bens que pertencem a toda humanidade, incluindo às futuras gerações, não podendo dessa forma ser objeto de apropriação por ninguém em particular, definindo a obrigação da sua proteção e preservação como forma de garantir o direito da humanidade em sua totalidade (MARUM, 2000, p. 13).

Para se ter um meio ambiente equilibrado é necessário a preservação da natureza de forma abrangente, ou seja, todos os seus recursos e elementos, sendo estes essenciais à vida humana bem como para a manutenção do equilíbrio ecológico. 
No Brasil, a Constituição Federal de 1988 elevou a questão ambiental a um patamar de proteção necessária à sadia qualidade de vida, incluindo o meio ambiente ecologicamente equilibrado, bem de uso comum do povo, como um direito fundamental já reconhecido internacionalmente na expressão de direitos humanos (COELHO; RIBEIRO, 2019, p.41).

É consenso, já por algum tempo, que os direitos fundamentais não se limitam aos estabelecidos no artigo $5^{\circ}$ da Constituição de 1988, estando diluídos em outros títulos e capítulos, expressa ou implicitamente, até mesmo em razão da abertura concedida pelo $\S 2^{\circ}$, do citado dispositivo, que, em redação clara, assim dispõe: "os direitos e garantias expressos nesta Constituição não excluem outros decorrentes do regime e dos princípios por ela adotados, ou dos tratados internacionais em que a República Federativa do Brasil seja parte" (THOMÉ, 2014, p. 123).

O artigo 225 da Constituição Federal pode ser considerado como núcleo fundador do direito de todos ao meio ambiente ecologicamente equilibrado:

Todos têm direito ao meio ambiente ecologicamente equilibrado, bem de uso comum do povo e essencial à sadia qualidade de vida, impondo-se ao Poder Público e à coletividade o dever de defendê-lo e preservá-lo para as presentes e futuras gerações

Sendo assim, ao considerar o meio ambiente como direito, com a qualidade de ser ecologicamente equilibrado, quis o constituinte tutelar não qualquer ambiente, mas aquele que resultasse de um equilíbrio entre as (dinâmicas) relações travadas entre o homem e a natureza e que, portanto, impusesse a proteção e defesa para as presentes e futuras gerações (DUARTE, 2006, p.92).

O meio ambiente é uma garantia da coletividade devendo ser protegido de forma mais severa uma vez que está diretamente ligado à qualidade de vida, bem como ao direito à vida. Sendo assim, prepondera o entendimento de que o meio ambiente é um direito fundamental indispensável ao bem estar humano.

É reconhecido que o cidadão tem o direito de usufruir de um ambiente equilibrado, todavia, esse exercício traz consigo o dever de uma utilização racional dos recursos ambientais. Embora exista intensa legislação sobre o tema, a proteção ambiental exige mais, na medida em que é apenas através da adoção de mecanismos de controle e aplicação da lei de forma eficaz que se poderão alcançar medidas sustentáveis de amparo ao meio ambiente. A constitucionalização do direito ambiental demonstra a importância que se reconhece ao tema. 
Todavia, essa importância apenas ganha força se for refletida na conduta social (BRASIL; FREITAS, 2019).

O poder Judiciário atuou de forma sensível em situações particulares referente a proteção ao meio ambiente, admitindo certa adaptação às formalidades do processo clássico. É importante mencionar que um processo para lidar com políticas públicas exige inúmeras soluções diversas do direito processual tradicional, uma vez que esse não proporciona uma necessária efetividade para uma adequada discussão sobre políticas públicas devido aos seus princípios e procedimentos tradicionais.

Muitas decisões em ação coletiva ambiental têm imposto a obrigação de sujeitar qualquer modificação na área afetada à prévia manifestação, ou orientação do órgão ambiental competente, ou ainda a de condicionar a prática de certos atos com repercussão ambiental à prévia autorização do órgão de fiscalização ambiental (ARENHART, 2021, p. 1054).

Talvez um dos casos brasileiro mais interessantes no campo de proteção ambiental seja o tratamento dado à questão da mineração do carvão na área de Criciúma/SC. Em 1993 o Ministério Público Federal ajuizou Ação Civil Pública junto À Justiça Federal de Criciúma pretendendo impor às rés, mineradoras e União sendo o total de 24 rés, a realização e a concretização de um projeto de recuperação ambiental da região degradada pela mineração (ARENHART, 2021, p. 1055).

Em janeiro de 2000, o então juiz federal Paulo Afonso Brum Vaz, titular na época da $1^{a}$ Vara Federal de Criciúma, proferiu sentença, com antecipação de tutela, condenando todas as empresas, a União e o Estado de SC a apresentarem, no prazo de seis meses, projeto de recuperação ambiental da região, com cronograma de execução para três anos, contemplando as áreas de depósito de rejeitos, áreas mineradas a céu aberto e minas abandonadas, bem como o desassoreamento, fixação de barrancas, descontaminação e retificação dos cursos d'água, além de outras obras que visem amenizar os danos sofridos principalmente pela população dos municípios sede (ARENHART, 2021, p. 1056).

Os réus recorreram da sentença e em outubro de 2002 foi decidido, pela desembargadora federal Maria de Fátima Freitas, relatora do processo, que a condenação das rés deveria ser mantida, com exceção da mineradora Nova Próspera Mineração S/A, uma vez que adquiriu a carbonífera depois que os danos já tinham ocorrido.

Paralelamente ao trâmite recursal, o Ministério Público Federal deu início à execução provisória da sentença. Embora a sentença estivesse sujeita a reexame necessário, foi 
autorizada em antecipação da tutela, o início dos atos executivos. A complexidade da matéria e da efetivação do comando sentencial, recomendou que o cumprimento se desdobrasse em várias fases, posteriormente desdobradas também em vários procedimentos autônomos, um para cada réu condenado (ARENHART, 2021, p. 1057).

A exploração do carvão, atualmente, ocorre de forma planejada com planos de recuperação de áreas de atuação das empresas ocorrendo em paralelo a extração e beneficiamento do carvão. Os avanços tecnológicos, métodos inovadores e equipamentos de última geração são utilizados atualmente na mineração de carvão e oferecem mais segurança aos trabalhadores em comparativo com os procedimentos de décadas passadas. Os resíduos resultantes da lavagem do carvão retornam ao seu local de origem, no subsolo, preenchendo os espaços vazios deixados pela extração do carvão e, o restante é depositado em locais previamente aprovados e adequados a tais disposições, atendendo as exigências para tais fins. 9 UNESC - Universidade do Extremo Sul Catarinense O processo de exploração das jazidas é automatizado, com o uso de minerador contínuo. Operado por controle remoto, permite que as paredes da mina mantenham-se uniformes, evitando as quedas de lascas de carvão. Com isso, há significativa redução de trabalhadores em subsolo com melhorias na qualidade de vida e redução no impacto ambiental (ZANETTE; CAMILO, 2018).

Os processos decorrentes da ACP do carvão impactaram positivamente nos processos de planejamento de recuperação dos danos ambientais durante o processo de extração mineral e após o fechamento das minas. Desde a constituição de Núcleo de Meio Ambiente pelo SIECESC que possibilitou discussão e planejamento de ações futuras a outros projetos que foram desenvolvidos em decorrência da referida ACP. O Termo de Ajustamento de Conduta (TAC) celebrado em 2005, entre o MPF, a Fundação do Meio Ambiente (FATMA) e as empresas mineradoras promoveu o início do processo formal de adequação das unidades em operação, da cadeia produtiva do carvão mineral. As atividades de adequação foram correlatas a todas as etapas da indústria minerária, desde a extração, passando pelo beneficiamento e incluindo o transporte e deposição final de rejeitos. O instrumento possibilitou também, que as empresas iniciassem um processo de implantação e certificação de seus Sistemas de Gestão Ambiental (SGA). Estas certificações, atualmente, são pré-requisitos nos contratos para fornecimento de carvão ao Complexo Termelétrico Jorge Lacerda de Capivari de Baixo. Atualmente, todas as empresas carboníferas possuem Sistema de Gestão Ambiental (SGA), com certificação ISO 14.001 (ZANETTE; CAMILO, 2018). 
A participação de especialistas na área, oferece aos sujeitos do processo, incluindo o juiz, contornos mais precisos do litígio e de possíveis soluções cabíveis. Essa intervenção é capaz de expor aspectos, problemas e interesses não percebidos inicialmente quando do ajuizamento da causa. É também capaz de mostrar alternativas de composição do conflito que funcionou em conflitos semelhantes ou que possuam viabilidade técnica (ARENHART, 2021, p. 1061).

É necessário em processos que discutem políticas públicas adaptações procedimentais. Especialmente em temas como os limites da coisa julgada, o princípio da congruência e a rigidez da sequência procedimental exigem revisitação à luz das necessidades de ampla participação no processo. Trata-se de oferecer um conjunto de técnicas e instrumentos processuais aptos a tornar viável a intervenção, de modo responsável, judicial em políticas públicas (ARENHART, 2021, p. 1063).

O processo estrutural é um meio que possibilita uma melhor e mais eficaz reorganização e adequação de um estado que viola sistematicamente o direito ao meio ambiente equilibrado, visando uma maior e real efetividade deste direito fundamental. Uma vez que os instrumentos processuais devem ser utilizados para resolver a lide em questão da maneira mais eficaz possível.

\section{CONSIDERAÇÕES FINAIS}

Deste modo, pode-se concluir que é necessário uma reestruturação com o intuito de prevenção para minimizar os danos ambientais. Para tanto a decisão estrutural pode ser o ponto de partida para essa reorganização, sendo necessário uma intervenção judicial, diante da incapacidade demonstrada pelas instituições administrativas e legislativas, que proporcione um diálogo e trace estratégias que alcancem um objetivo efetivo.

O processo estrutural é instrumento adequado para alcançar tal objetivo, visto que, neste caso, é necessário uma decisão que estabeleça os caminhos necessários para alcançar um meio ambiente de fato equilibrado conforme assegurado constitucionalmente, sendo essencial que o poder judiciário supervisione para que possa propiciar que as questões que apareçam no decorrer da reestruturação possam ser solucionadas.

Deste modo é importante observar que o lapso temporal para efetivação das decisões estruturais não podem ser comparadas ao tempo de um procedimento comum, visto que se 
trata de casos complexos que visão uma reestruturação, sendo necessário um planejamento e um tempo razoável para que o objetivo traçado possa ser alcançado.

Como pode ser notado no caso Brown v. Board of Education, no qual a decisão foi proferida em 1954, entretanto demorou anos para que a segregação racial fosse eliminada nas escolas públicas norte americanas. Entretanto, essa decisão produziu efeitos positivos e simbolicos, não apenas referente a segregação racial em escolas, impulsionou diversos movimentos dos direitos civis dos negros nos Estados Unidos.

As violações e degradações do meio ambiente são consequência de falhas estruturais do Estado e das instituições responsáveis, sendo necessária a adoção de medidas estruturais flexíveis visando, em face da reiterada inércia e omissão estatal, garantir o direito ao meio ambiente equilibrado para as atuais e futuras gerações.

\section{REFERENCIAS}

ARAUJO, Luiz Alberto David. Curso de direito constitucional. 3. ed. São Paulo: Saraiva, 1999.

ARAÚJO, Vanessa Mascarenhas de. A sentença estruturante e o pleno acesso à justiça: em busca das adequadas soluções dos litígios coletivos complexos e da efetividade das políticas públicas. Organização: Sérgio Cruz Arenhart, Marcos Felix Jobim. Salvador: Juspodivm, 2021.

ARENHART. Sérgio Cruz. Decisões estruturais no direito processual civil brasileiro. São Paulo: Revista dos Tribunais, 2013.

ARENHART, Sérgio Cruz. Processos estruturais no direito brasileiro: reflexões a partir do caso da ACP do carvão. In: Sérgio Cruz Arenhart, Marcos Felix Jobim [org.] Processos estruturais. Salvador: Juspodivm, 2021

BRASIL, Deilton Ribeiro; FREITAS, Érica Patricia. Processo coletivo e os mecanimos de proteção ao meio ambiente e à sustentabilidade. In: Dierle Nunes; Fabrício Veiga Costa; Magno Federici Gomes [org.] Processo coletivo, desenvolvimento sustentável e tutela diferenciada dos direitos fundamentais. Porto Alegre: Editora Fi, 2019. Disponível em: http://domhelder.edu.br/wp-

content/uploads/2020/03/LIVRO\%201\%20PROCESSO\%20COLETIVO\%20E\%20SUSTEN TABILIDADE-PUBLICADO.pdf. Acesso em: 25 mar. 2021

COELHO, Inocêncio Martires. As ideias de Peter Haberle e a abertura da interpretação constitucional no direito brasileiro. Revista de Informação Legislativa, Brasília, a. 35, n. 137, p. 157-164, jan./mar. 1998. Disponível em: 
https://www2.senado.leg.br/bdsf/bitstream/handle/id/343/r137-

16.pdf?sequence $=4 \&$ is Allowed=y. Acesso em: 23 mar. 2021.

COELHO, Ariadne Elloise; RIBEIRO, Luiz Gustavo Gonçalves. A tutela do ambiente e o problema do controle jurisdicional de políticas públicas: entre o ativismo e o passivismo. In: Dierle Nunes; Fabrício Veiga Costa; Magno Federici Gomes [org.] Processo coletivo, desenvolvimento sustentável e tutela diferenciada dos direitos fundamentais. Porto Alegre: Editora Fi, 2019. Disponível em: http://domhelder.edu.br/wpcontent/uploads/2020/03/LIVRO\%201\%20PROCESSO\%20COLETIVO\%20E\%20SUSTEN TABILIDADE-PUBLICADO.pdf. Acesso em: 25 mar. 2021

DIDIER, Fredie Jr.; ZANETI, Hermes; OLIVEIRA, Rafael Alexandria. Sérgio Cruz Arenhart, Marcos Felix Jobim. [org] Elementos para uma teoria do processo estrutural aplicada ao processo civil brasileiro. Salvador: Juspodivm, 2021

DUARTE, Marise Costa de Souza. Meio ambiente sadio: direito fundamental em crise. 2. ed. Curitiba: Juruá, 2006.

FISS, Owen. Um novo processo civil. São Paulo: Revista dos Tribunais, 2004.

GALDINO, Matheus Souza. Breves reflexões sobre as consequências de uma compreensão teleológica dos fatos para a teoria do processo estrutural. Sérgio Cruz Arenhart, Marcos Felix Jobim. 2. ed. Processos estruturais. Salvador: Juspodivm, 2019.

JOBIM, Marcos Felix. Reflexões sobre a necessidade de uma teoria dos litígios estruturais: bases de uma possível construção. ARENHART. Sérgio Cruz, JOBIM, Marcos Felix [org.] Processos Estruturais. Salvador: Juspodivm, 2021.

JOBIM, Marcos Felix. Medidas estruturantes: da Suprema Corte Estadunidense ao Supremo Tribunal Federal. Porto Alegre: Livraria do Advogado, 2013.

MARUM, Jorge Alberto de Oliveira. Meio ambiente e direitos humanos. Ministério Público de São Paulo, 2000. Disponível em:

https://www.lexml.gov.br/urn/urn:lex:br:rede.virtual.bibliotecas:artigo.revista:2002;10006385 37 . Acesso em: 23 mar. 2021.

SARLET, Ingo Wolfgang. Dignidade da pessoa humana e direitos fundamentais na Constituição Federal de 1988. 9. ed. São Paulo: Livraria do Advogado, 2012.

SARLET, Ingo Wolfgang. Sérgio Cruz Arenhart, Marcos Felix Jobim [org] Direitos Fundamentais sociais e mínimo existencial: notas sobre um possível papel da assim chamada decisão estruturante na perspectiva da jurisdição constitucional. Salvador: Juspodivm, 2021

SILVA, José Afonso da. Curso de direito constitucional positivo. 28. ed. Brasil: Malheiros, 2007. 
SILVA NETO, Francisco de Barros e. Breves considerações sobre os processos estruturais. Sérgio Cruz Arenhart, Marcos Felix Jobim [org.] Processos estruturais. Salvador: Juspodivm, 2021.

THOMÉ, Romeu. O princípio da vedação do retrocesso socioambiental no contexto da sociedade de risco. Salvador: JusPodivm, 2014.

TOSTES. André. Sistema de legislação ambiental. Rio de Janeiro: Vozes, 1994

VIOLIN, Jordão. Holt vs Sarver e a reforma do sistema prisional de Arkansas. Sérgio Cruz Arenhart, Marcos Felix Jobim [org] Processos estruturais. Salvador: Juspodivm, 2021

VITORELLI, Edilson. Sérgio Cruz Arenhart, Marcos Felix Jobim [org.] Litígios estruturais: decisão e implementação de mudanças socialmente relevantes pela via processual. Salvador: Juspodivm, 2021

ZANETTE, Eduardo Netto; CAMILO, Silvio Parodi Oliveira. A recuperação ambiental a partir da Ação Civil Pública no contexto da exploração do carvão mineral no sul de Santa Catarina. Disponível em: file://C:/Users/User/Downloads/4682-12757-1-SM.pdf . Acesso em: 25 mar. 2021. 